\title{
General anesthesia does not impair simulator dri- ving skills in volunteers in the immediate recovery period - a pilot study
}

\author{
[L'anesthésie générale n'altère pas les habiletés de conduite sur simulateur chez des \\ volontaires en récupération immédiate - une étude pilote]
}

David R. Sinclair MD, ${ }^{*}$ Frances Chung FrCPC, $\dagger$ Alison Smiley PhD

Purpose: The current recommendations to refrain from driving for $24 \mathrm{hr}$ after general anesthesia (GA) lack evidence. Our objective was to measure impairment of driving performance at various time intervals after anesthesia using driving impairment at different blood alcohol concentrations (BAC) as a gold standard for comparison.

Methods: Institutional Review Board approval was obtained. A crossover design, within subject comparison was used. Twelve volunteers were randomized to three treatments: GA, alcohol, and no drug. Psychomotor recovery was assessed by Digit Symbol Substitution Test (DSST) and Trieger Dot Test (TDT). On the anesthetic day, GA was induced with propofol $2.5 \mathrm{mg} \cdot \mathrm{kg}^{-1}$ and fentanyl $\mathrm{\mu g} \cdot \mathrm{kg}^{-1}$ and maintained with $\mathrm{N}_{2} \mathrm{O}-\mathrm{O}_{2}$ 50:50 and approximately one minimum alveolar concentration of desflurane by spontaneous ventilation for $30 \mathrm{~min}$. Driving simulator test runs occurred at two, three, four, and $24 \mathrm{hr}$ postanesthesia. On the alcohol treatment day, a vodka and orange juice beverage was administered to reach the legal limit for BAC in the province of Ontario, Canada (BAC 0.08\%). On the control day, no drug was given. Driving simulator test runs corresponded to the same time of day as the postanesthetic test runs. Two-way analysis of variance for dependent samples (ANOVA) was performed using the SAS program. $P$ values of less than 0.05 were considered significant.

Results: There was no significant difference in postanesthetic driving skills at two, three, and four hours postanesthesia, and the corresponding control sessions. There was no significant difference among the three sessions with respect to pen and paper tests of psychomotor performance. Performance during the alcohol session differed significantly from that during the control and postanesthetic sessions.

Conclusion: Certain driving skills return by two hours after one half hour of GA of propofol, desflurane, and fentanyl in a group of young volunteers.
Objectif : La recommandation courante restreignant la conduite pendant 24 h après une anesthésie générale (AG) manque de preuve. Notre objectif était de mesurer l'altération des habiletés de conduite à différents intervalles de temps après l'anesthésie en utilisant la détérioration de la conduite selon divers taux d'alcoolémie comme référence.

Méthode : Nous avons obtenu l'approbation du Comité d'examen de l'établissement. Un devis croisé avec comparaison intra-sujets a été utilisé. Douze volontaires ont reçu trois traitements au hasard : AG, alcool et absence de médicament. La récupération psychomotrice a été évaluée par le test de substitution de codes (TSC) et le Trieger Dot Test (TDT). Le jour de l'anesthésie, l'AG a été induite avec $2,5 \mathrm{mg} \cdot \mathrm{kg}^{-1}$ de propofol et I $\mu \mathrm{g} \cdot \mathrm{kg}^{-1}$ de fentanyl et maintenue avec un mélange à $50 \%$ de $\mathrm{N}_{2} \mathrm{O}_{-} \mathrm{O}_{2}$ et environ une CAM de desflurane par ventilation spontanée pendant $30 \mathrm{~min}$. La série de tests de simulation de conduite a eu lieu deux, trois, quatre et 24 h après l'anesthésie. Le jour où on a donné l'alcool, une boisson faite de vodka et de jus d'orange a permis d'atteindre le taux d'alcoolémie limite accepté en Ontario, Canada (0,08\%). Le jour témoin, aucun médicament n'a été administré. La série de tests de simulation de conduite s'est faite aux mêmes intervalles de temps que la série réalisée le jour de l'anesthésie. Une analyse de variance à deux facteurs pour variables dépendantes (ANOVA) a été réalisée avec l'usage du programme SAS. Les valeurs de $P$ de moins de 0,05 ont été considérées significatives.

Résultats : II n'y a pas eu de différence significative entre les habiletés postanesthésiques testées à deux, trois et quatre heures après l'anesthésie et pendant les sessions témoins correspondantes. II n'y a pas eu de différence significative entre les trois sessions quant à la performance psychomotrice aux tests d'écriture. La performance pendant la session sous alcool a présenté une différence significative par rapport aux deux autres sessions.

From the Department of Anesthesiology, ${ }^{*}$ University of Florida, Jacksonville, Florida, USA, the Department of Anesthesia, $\dagger$ Toronto Western Hospital, and the Human Factors North Inc., † Toronto, Ontario, Canada. Address correspondence to: Dr. Frances Chung, Department of Anesthesia, Toronto Western Hospital, 399 Bathurst St., EC 2-046,

Toronto, Ontario M5T 2S8, Canada. Phone: 416-603-5118; Fax: 416-603-6494; E-mail: frances.chung@uhn.on.ca

This study was supported by a grant from the Society for Ambulatory Anesthesia Accepted for publication July 10, 2002.

Revision accepted November 13, 2002. 
Conclusion : Certaines habiletés de conduite sont revenues à la normale deux heures après une AG d'une demi-heure réalisée avec du propofol, du desflurane et du fentanyl chez un groupe de jeunes volontaires.

A MBULATORY anesthesia has grown rapidly over the past decade. ${ }^{1}$ Much of its success can be attributed to the advent of new, shorter acting anesthetic agents providing faster recovery and earlier return to normal daily activity with minimal postanesthetic cognitive impairment. Despite the increased use of new agents, recommendations to refrain from driving for $24 \mathrm{hr}$ or signing legal documents after general anesthesia (GA) remain. ${ }^{2,3}$ Evidence for such advice is lacking and may not reflect the more rapid recovery that is achieved following the administration of shorter-acting agents.

In 1977, Korttila et al. administered GA to healthy volunteers and assessed their postanesthetic psychomotor impairment. ${ }^{4} \mathrm{He}$ concluded that patients should not drive or operate machinery for at least seven hours, even after brief periods of halothane and enflurane anesthesia. Based upon psychomotor test performance, other studies have drawn conclusions about driving impairment after the administration of anesthetic drugs. ${ }^{5-12}$ Recommendations to avoid driving ranged from one hour to six hours. These studies, however, did not involve the administration of a balanced general anesthetic.

Thus, driving performance following a balanced general anesthetic utilizing the new, short-acting agents, propofol and desflurane remains unclear. We hypothesized that driving performance returns promptly after ambulatory anesthesia. Our objective was to measure impairment of driving performance at various time intervals after anesthesia using driving impairment at different blood alcohol concentrations (BAC) as a gold standard for comparison.

\section{Materials and methods}

Institutional Review Board approval was obtained. Volunteers were recruited via advertisements in the city newspaper and hospital bulletin board. Inclusion criteria included age $2 \mathrm{l}-45 \mathrm{yr}$ and possession of a valid driver's license. An initial telephone interview, conducted by a trained research assistant, was used as a preliminary screening step. Exclusion criteria included a history of gastroesophageal reflux, ASA physical status III or IV, obesity (body mass index > 35), chronic benzodiazepine or opioid use, and light drinking. Moderate and heavy drinkers were selected according to the quantity- frequency-variability-classification, ${ }^{13}$ which uses a numerical system to classify drinkers based upon how often they drink beer, wine, or whisky, and how often they drink certain amounts of various kinds of alcohol. The volunteers were scheduled for a preanesthetic evaluation with the anesthesiologist (D.S.) within one week of the screening telephone interview to undergo a history and physical examination, discuss the details of the study, verify the validity of the driver's license, and obtain a written consent form. The volunteers were advised to avoid food after midnight prior to the general anesthetic but to have a light breakfast (toast, juice, but no coffee) prior to the control and alcohol sessions. They were also instructed to abstain from alcohol use for $48 \mathrm{hr}$ prior to each treatment day, avoid recreational drugs during the course of the study, and arrange for an escort home after general anesthesia. Within one week of the preanesthetic interview, the volunteers attended two three-hour training sessions on the driving simulator, separated by a minimum of two days. These training sessions were intended to reduce the learning effect and familiarize each volunteer with the driving simulator.

A prospective, randomized within-subjects design of three treatments (no drug, GA, and alcohol) was

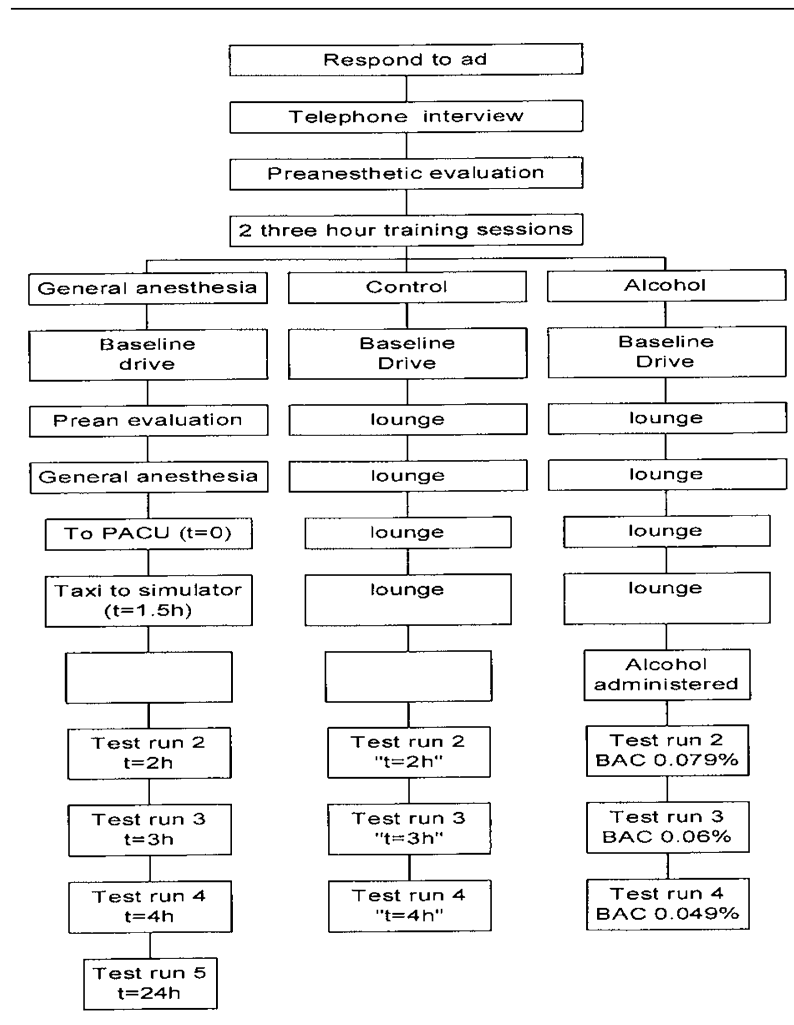

FIGURE 1 Methods flow chart. 
conducted (Figure 1). The volunteers were randomized by a computer-generated list to the sequence of the three treatment sessions at the end of the second training sessions. Two to four days separated the last training session from the first treatment session and four to seven days separated each treatment session.

The STISIM interactive driving simulator (Systems Technology Inc. version 8.16), located five minutes away from the hospital, was used for testing. It is a reliable and sensitive tool for measuring the effects of alcohol. ${ }^{\mathrm{A}}$ It is composed of three 17 inch monitors which allow a wide angle roadway display. The subject is seated in front of the monitors and uses a steering wheel, accelerator, and brakes to control the vehicle. The road scene display changes in accordance with the subject's actions. Sound feedback related to speed and collisions is also provided. The scenario included rural, suburban and urban road sections. The subject encountered vehicles which had to be passed, and vehicles which pulled out onto the road suddenly and had to be avoided. The urban section included intersections with traffic signals at which pedestrians crossed. Volunteers perform a peripheral signal cancellation task while driving, in which they use a turn signal to respond to a symbol to the right or the left of the road scene, in their peripheral vision. This task is intended to simulate demands on the driver to attend to other traffic and pedestrians. The driving scenarios and divided attention task concepts were developed by Dr. Herbert Moskowitz. At the end of each run, test results are printed based on measures of lane position, speed, number of collisions, and response time to peripheral signals. Each simulation run lasts $20 \mathrm{~min}$.

The volunteers did a baseline driving simulator run upon arrival at the driving simulator facility each morning. The volunteers walked to The Toronto Western Hospital after completion of their baseline drive. The preanesthetic record was reviewed and conformity to study requirements was verified. Two psychomotor tests were administered to assess baseline psychomotor performance. The trieger dot test (TDT) tests fine motor coordination and perception. ${ }^{14}$ Volunteers were required to connect a pattern of dots at $12-13 \mathrm{~mm}$ intervals. The number of dots that were missed was recorded. The second psychomotor test, the digit-symbol substitution test (DSST), presented a code of nine matched digits and symbols at the top of the test sheet. ${ }^{15}$ Volunteers were required to record the

\footnotetext{
A Moskowitz H, Burns M, Fiorentino D, Smiley A, Zador P. Driver Characteristics and Impairment at Various BACs. Final Report, National Highway Traffic Safety Administration, U.S. Department of Transportation, 1999.
}

symbol below a digit to match the code. The number of correct items completed in $90 \mathrm{sec}$ was the score. An $i v$ catheter was inserted in a hand vein. No premedication was administered.

The standard monitors (electrocardiograph, pulse oximeter, non-invasive blood pressure, capnography, temperature, and inhaled anesthetic concentration of the volatile anesthetic) were applied and the volunteers were preoxygenated with $100 \%$ oxygen by facemask. Anesthesia was induced with propofol 2.5 $\mathrm{mg} \cdot \mathrm{kg}^{-1}$ and fentanyl $1 \mu \mathrm{g} \cdot \mathrm{kg}^{-1}$ and maintained with $\mathrm{N}_{2} \mathrm{O}-\mathrm{O}_{2} 50: 50$ and approximately one minimum alveolar concentration of desflurane (3.5-4\% end-tidal) by facemask for $30 \mathrm{~min}$. End-tidal carbon dioxide was maintained between $40-50 \mathrm{mmHg}$ during spontaneous ventilation. At the end of the anesthetic, all inhalation agents were turned off $(t=0)$. The volunteers were transported with oxygen by facemask to the postanesthetic care unit. The volunteers were considered ready for hospital discharge after $100 \mathrm{~min}$, at which time they were escorted (D.S.) by taxi to the driving simulator facility. The driving simulator runs occurred upon arrival at the facility $(\mathrm{t}=\mathrm{two}$ hours $)$, and at one $(t=$ three hours $)$, and two hours ( $t=$ four hours) after arrival. The volunteers completed the TDT and the DSST prior to each test run. The volunteers were transported home by taxi, accompanied by an escort. The final test run in the anesthetic group occurred the following day ( $24 \mathrm{hr}$ after $\mathrm{t}=$ two hours). On that day, the volunteers arrived at the facility at the same time of day as the anesthetic treatment session to complete the $20 \mathrm{~min}$ driving simulator run. No baseline run occurred on these mornings.

Prior to the baseline run on the day of alcohol treatment, conformity to the study requirements was verified using a questionnaire. Since circadian rhythm affects performance, tests on the alcohol and control days were administered at the same times of the day as tests on the anesthetic treatment days. Thus, on the alcohol treatment day, the volunteers waited approximately three hours in a waiting room until the alcohol was administered $30 \mathrm{~min}$ prior to the time corresponding to the $\mathrm{t}=$ two hours time on the anesthetic treatment day. Alcohol was administered in three drinks over a 30 -min period based upon a calculation using a method developed by Dr. Herbert Moskowitz (Appendix available at www.cja-jca.org as "additional material"). The alcohol was equal parts 80 proof vodka and orange juice. The alcohol dose level was $0.68 \mathrm{~g}$ alcohol $\cdot \mathrm{kg}^{-1}$ for a target BAC $0.08 \%$, the legal blood alcohol limit. Following alcohol ingestion, BAC decreases by approximately $0.015 \%$ per hour. Therefore, subsequent driving simulator tests 
TABLE I Demographics

\begin{tabular}{llll}
\hline & $\begin{array}{l}\text { Males } \\
(n=6)\end{array}$ & $\begin{array}{l}\text { Females } \\
(n=6)\end{array}$ & $\begin{array}{l}\text { Total } \\
(n=12)\end{array}$ \\
\hline Age $(\mathrm{yr})$ & $29 \pm 7$ & $33 \pm 8$ & $31 \pm 7$ \\
Height $(\mathrm{cm})$ & $174 \pm 8$ & $171 \pm 8$ & $172 \pm 8$ \\
Weight $(\mathrm{kg})$ & $74 \pm 11$ & $64 \pm 11$ & $69 \pm 12$ \\
BMI $\left(\mathrm{kg} \cdot \mathrm{m}^{2}\right)$ & $24 \pm 3$ & $22 \pm 3$ & $23 \pm 3$ \\
Driving experiences $(\mathrm{yr})$ & $11 \pm 5$ & $13 \pm 5$ & $12 \pm 5$ \\
Moderate/heavy drinkers & $4 / 2$ & $4 / 2$ & $8 / 4$ \\
\hline
\end{tabular}

$\mathrm{BMI}=$ body mass index. Values are expressed as mean $\pm \mathrm{SD}$.

TABLE II Blood alcohol concentration (\%)

\begin{tabular}{llll}
\hline $\begin{array}{l}\text { Corresponding } \\
\text { postanesthesia time }\end{array}$ & $\begin{array}{l}\text { Males } \\
(n=6)\end{array}$ & $\begin{array}{l}\text { Females } \\
(n=6)\end{array}$ & $\begin{array}{l}\text { Total } \\
(n=12)\end{array}$ \\
\hline Two hours & $0.082 \pm 0.008$ & $0.075 \pm 0.01$ & $0.079 \pm 0.009$ \\
Three hours & $0.063 \pm 0.002$ & $0.058 \pm 0.006$ & $0.06 \pm 0.056$ \\
Four hours & $0.05 \pm 0.003$ & $0.048 \pm 0.007$ & $0.049 \pm 0.005$ \\
\hline
\end{tabular}

Values are expressed as mean $\pm \mathrm{SD}$.

occurred at a BAC of $0.065 \%$, one hour after ingestion, and a $\mathrm{BAC}$ of $0.05 \%$, two hours after ingestion. The volunteers completed the TDT and the DSST prior to each test run. BAC was monitored by a breathalyzer (Alco-Sensor IV, Intoximeters Inc., St. Louis, Missouri, USA) which is accurate to within \pm $5 \%$. At a BAC of 0 , approximately seven hours after ingestion, the volunteers were driven home by taxi.

Volunteers were also required to undergo the driving simulator test without receiving any drug. On that day, the volunteers waited in a lounge after performing the baseline driving simulator test run. The subsequent test runs on the driving simulator occurred at the time of day corresponding to $t=$ two hours, $t=$ three hours, and $t=$ four hours after GA. Once again, the volunteers completed the TDT and DSST prior to each test run and were driven home by taxi.

\section{Statistical analysis}

Two-way analysis of variance for dependent samples (ANOVA) was performed for all continuous variables. Post hoc pair-wise comparisons by Bonferroni's method were performed within and between treatment groups, when a significant difference was noted. Categorical variables were analyzed using the Chi-squared test. $P$ values of less than 0.05 were considered statistically significant. Data were stored and subsequent analysis performed using the SAS program.

\section{Results}

Twelve healthy volunteers were recruited (Table I). Ten volunteers completed the 24 -hr postanesthesia run.

On the alcohol treatment day, prior to simulator testing, BAC (mean \pm SD) was $0.079 \% \pm 0.009 \%$. BAC at one and two hours after consumption were $0.06 \% \pm$ $0.005 \%$ and $0.049 \% \pm 0.05 \%$, respectively (Table II). There were no significant differences in mean response time (MRT), number of collisions, number of times over the speed limit, and lane deviation among the three treatment sessions (Figures 2-5).

\section{GA vs control}

I. MRT

MRT measured the driver's ability to respond to a peripheral signal. There was no statistically significant difference in MRT between the GA and control session at any postanesthesia time interval. MRT was $5.3 \%, 0.9 \%$, and $0.5 \%$ greater at two, three, and four hours postanesthesia, respectively, than the corresponding control value.

\section{NUMBER OF COLLISIONS}

Crashes, into an adjacent vehicle or pedestrian, did not differ significantly between the GA and control sessions at any postanesthesia time interval. At two and three hours postanesthesia, the number of collisions was less than the corresponding control values. However, at four hours postanesthesia, the number of collisions had risen $17 \%$ above the control value ( 1.36 vs 1.16 collisions, respectively).

\section{NUMBER OF TIMES OVER THE SPEED LIMIT}

The speed limit was posted along the roadway and varied according to the scenario (rural ps urban setting). Although a significant difference did not exist between the GA and control session at any postanesthesia interval, the number of times the speed limit was exceeded was always greater during the control session than the corresponding postanesthesia session. The number of times the speed limit was exceeded had increased by $8 \%$ above baseline values at two hours postanesthesia.

\section{LANE DEVIATION}

Lane deviation measured the driver's ability to maintain lane position. GA did not significantly impair lane position control, compared to the control session, at any postanesthesia time interval. Despite an initial $0.7 \%$ decrease at two hours postanesthesia, lane deviation peaked at $2.8 \%$ above baseline at three hours postanesthesia. By four hours postanesthesia, lane deviation had decreased to $4.3 \%$ below baseline. 


\section{Mean Response Time}

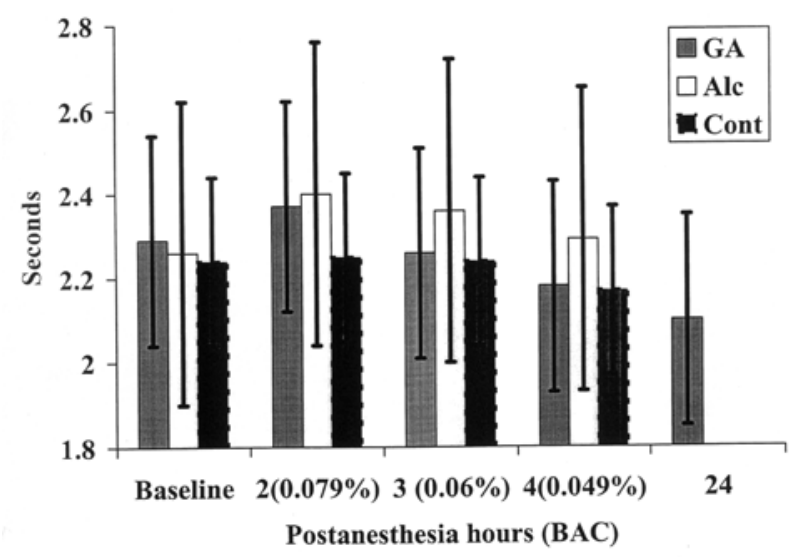

FIGURE 2 Mean response times at baseline, two, three, four, and $24 \mathrm{hr}$ after anesthesia, and corresponding blood alcohol concentration (BAC).

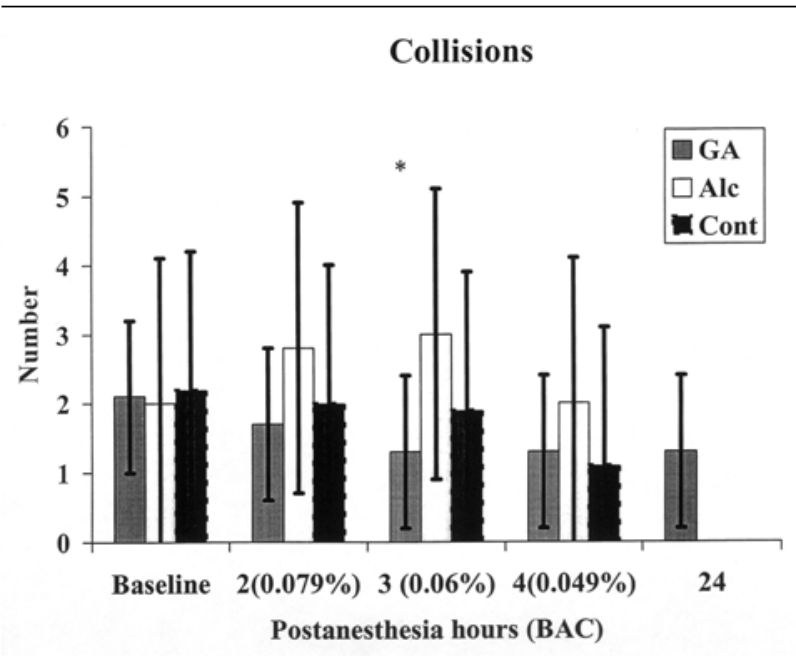

FIGURE 3 The number of collisions at baseline, two, three, four, and $24 \mathrm{hr}$ after anesthesia, and corresponding blood alcohol concentration $(\mathrm{BAC}) .{ }^{*} P=0.049$ general anesthesia $v s$ alcohol.

\section{Alcobol vs control}

I. MRT

There was no statistically significant difference in MRT between the alcohol and control session at any BAC. At a BAC $0.079 \%$, MRT increased by $6.6 \%$ above the baseline value, decreasing steadily to a $1.3 \%$ increase at BAC 0.049\%.

\section{NUMBER OF COLLISIONS}

The number of collisions did not differ significantly between the alcohol and control session. The number

\section{Times Over Speed Limit}

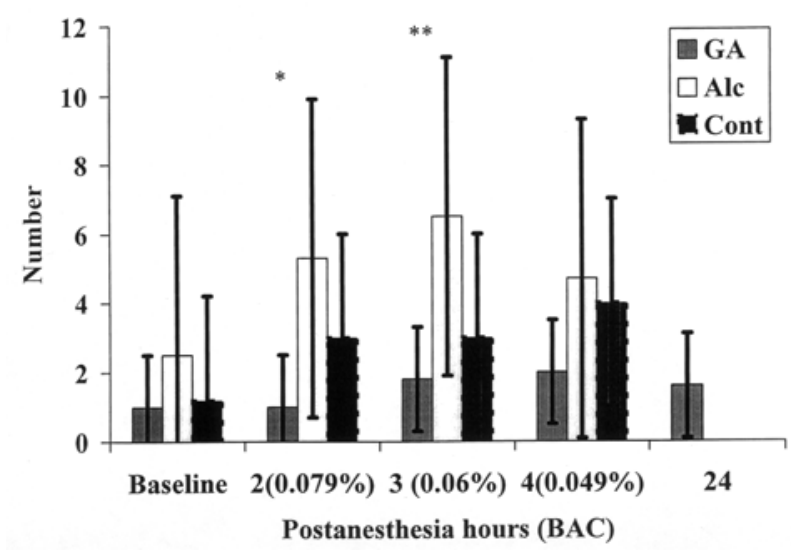

FIGURE 4 The number of times over the speed limit at baseline, two, three, four, and $24 \mathrm{hr}$ after anesthesia, and corresponding blood alcohol concentration (BAC). ${ }^{*} P=0.042$ and ${ }^{*} P=$ 0.019 general anesthesia vs alcohol.

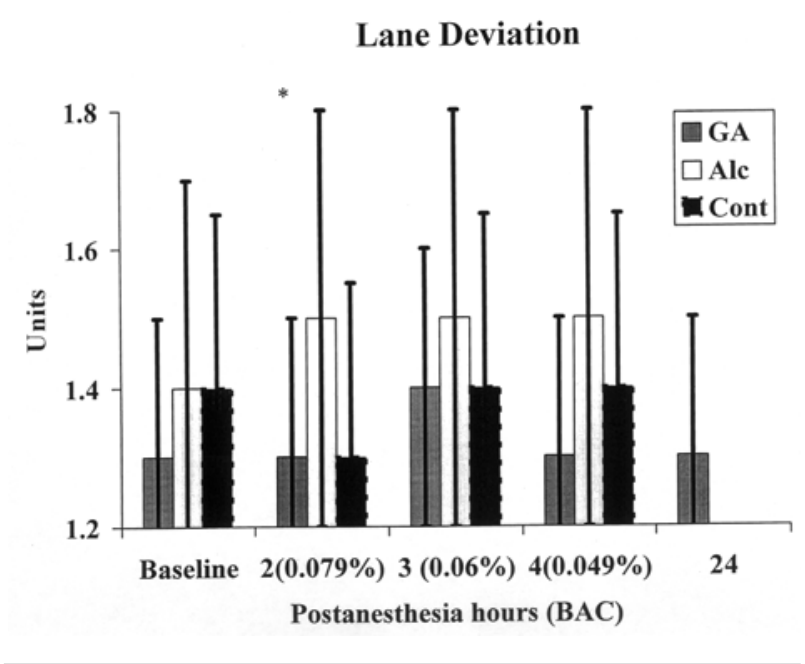

FIGURE 5 The degree of lane deviation at baseline, two, three, four, and $24 \mathrm{hr}$ after anesthesia, and corresponding blood alcohol concentration $(\mathrm{BAC}) .{ }^{*} \mathrm{P}=0.006$ control $v s$ alcohol.

of collisions increased by $86 \%$ at BAC $0.079 \%$ compared to baseline.

\section{NUMBER OF TIMES OVER THE SPEED LIMIT}

Although a significant difference did not exist between the alcohol and control session, the number of times the speed limit was exceeded increased by $112 \%$ at BAC $0.079 \%$. An additional $48 \%$ increase occurred at BAC $0.06 \%$ compared to $0.079 \%$. 


\section{LANE DEVIATION}

Lane deviation differed significantly between the alcohol and control session at BAC 0.079\% $(P=0.006)$. At this level, lane deviation increased by $11 \%$ above baseline. From this peak, it decreased steadily to $6.3 \%$ above baseline at BAC $0.049 \%$.

\section{GA vs alcohol}

I. MRT

There was no statistically significant difference in MRT between the GA and alcohol session at any corresponding time. Following peak increases above baseline at two hours postanesthesia and BAC $0.079 \%$ of $5.3 \%$ and $6.6 \%$, respectively, the GA session was associated with a more rapid return towards baseline levels.

\section{NUMBER OF COLLISIONS}

At BAC $0.079 \%$, there was more than a two-fold difference in the number of collisions compared to two hours postanesthesia. The number of collisions differed significantly between the GA and alcohol session at three hours postanesthesia and the corresponding BAC $0.06 \%(P=0.049)$.

\section{NUMBER OF TIMES OVER THE SPEED LIMIT}

A significant difference existed between the GA and alcohol session at two hours postanesthesia and a BAC $0.079 \%(P=0.042)$, and three hours postanesthesia and BAC $0.06 \%(P=0.019)$. At each time, there was more than a three-fold increase in the number of times the speed limit was exceeded among the alcohol session compared to the GA session.

\section{LANE DEVIATION}

Lane deviation did not differ significantly between the GA and alcohol session under any corresponding conditions.

\section{Twenty-four hour postanesthesia drive}

At 24-hr postanesthesia, driving performance had returned to baseline levels except for the number of times the speed limit was exceeded, where there was a $60 \%$ increase ( $1.6 \mathrm{vs} 1$, respectively).

\section{Pen and paper}

There was no significant difference among the three sessions with respect to the number of correct digitsymbol substitutions and the number of missed dots. The highest number of correct digit-symbol substitutions occurred at 24-hr postanesthesia. The number of missed dots remained at baseline levels at 24-hr postanesthesia.

\section{Discussion}

This study was designed to compare postanesthetic driving impairment to that caused by different BAC. In the province of Ontario, Canada, a BAC > $0.08 \%$ results in a fine and a court appearance before a judge. The driver's license is suspended for 90 days and the vehicle is impounded. At a $\mathrm{BAC} \leq 0.08$ or $\geq 0.05$, the driver's license is suspended for $12 \mathrm{hr}$. At a $\mathrm{BAC}<$ 0.05 , there is no penalty.

Driving performance was assessed by four driving performance variables. MRT measured a driver's ability to divide attention among competing tasks. Lapses in attention, resulting in increases in MRT, can lead to an increase in collisions. Lane deviation measured a driver's ability to maintain lane position. Exceeding the speed limit can be associated with increased swerving within the lane.

There was no statistically significant difference with respect to the four driving performance variables between two, three, and four hours postanesthesia and the corresponding control sessions, respectively. When comparing the alcohol and control session, statistical significance was achieved in lane deviation at BAC $0.079 \%(P=0.006)$. The GA and alcohol sessions were significantly different at two hours postanesthesia and a BAC $0.079 \%(P=0.042)$ in terms of the number of collisions, and at three hours postanesthesia and BAC $0.06 \%(P=0.019)$ in terms of the number of times the speed limit was exceeded. Driving skills and pen and paper psychomotor test performances were not significantly impaired at 24-hr.

A previous study comparing the degree of subjective and behavioural impairment caused by often-used sedative/analgesic combinations in ambulatory surgery suggested that midazolam was the key drug in producing prolonged psychomotor and subjective impairment when compared to fentanyl and propofol. ${ }^{16}$ The omission of midazolam from our study may account for the lack of significant impairment at two, three, and four hours postanesthesia.

The speed limit was exceeded fewer times at three hours postanesthesia during the control session. This contradicts a previous study in which 20 volunteers who received halothane or enflurane drove significantly faster on repeated testing using the Sim-L-car. ${ }^{4}$ However, the repetition of the Sim-L-car roadway scene may have facilitated driving faster on repeated testing. Perhaps drivers in the postanesthetic period were more fatigued, due to their treatment, and less motivated to drive quickly.

Lane deviation differed significantly between the alcohol and control sessions at BAC $0.079 \%(P=$ 0.006). Alcohol has been shown to have significant 
effects on lane position control. ${ }^{\mathrm{B}}$ In our study, the number of times the speed limit was exceeded increased by $112 \%$ at BAC $0.079 \%$, supporting the relationship between impaired lane position control and increased number of times the speed limit was exceeded following alcohol ingestion. The significant number of times the speed limit was exceeded at BAC $0.06 \%$ is consistent with reports of BAC lower than $0.08 \%$ impairing the accuracy of speed control and judgement of speed.

BAC of $0.07 \%$ to $0.09 \%$ cause significant impairment of divided-attention performance. ${ }^{\mathrm{B}}$ Our study demonstrates that MRT was sensitive to the effects of GA. However, MRT decreased toward control levels at a faster rate in the postanesthetic period than following alcohol ingestion, suggesting a greater sensitivity of MRT to the effects of alcohol than GA or that GA wears off more rapidly than alcohol.

Using the Post Anesthetic Discharge Scoring System, most patients can be discharged from the ambulatory surgery unit within two hours after surgery. ${ }^{17}$ In fact, some patients drive within $24 \mathrm{hr}$ despite recommendations to refrain. ${ }^{18}$ Further studies are required in order to make recommendations regarding resumption of driving in the postanesthetic period.

Driving skills at $24 \mathrm{hr}$ postanesthesia remain unexplored. Previous studies discontinued the driving simulator test runs prior to eight hours postanesthesia, extrapolating $24 \mathrm{hr}$ driving performance., ${ }^{4,19}$ The metabolism and elimination of the propofol, fentanyl, and deflurane by $24 \mathrm{hr}$ postanesthesia most likely accounted for the return of driving skills. At 24-hr postanesthesia, there was a $60 \%$ increase in the number of times the speed limit was exceeded compared to the baseline value. Although the percentage increase was large, the actual numbers (1.6 vs 1 , respectively) may be small enough to be of little clinical concern.

DSST and TDT did not show a significant difference in psychomotor impairment between the GA and alcohol sessions at anytime interval. In addition, there was no difference between the control and alcohol session. Our results suggest that opinions on driving performance should not be derived from pen and paper psychomotor tests. Psychomotor tests of higher cognitive function, such as the choice reaction test, seem to be

B Moskowitz H, Robinson C (SRA Technologies, Inc., Alexandria, VA). Effects of Low Doses of Alcohol on Driving-related Skills: A Review of the Evidence. National Highway Traffic Safety Administration; 1988. Report No. DOT HS 807 280, Contact No. DTNH22-84-C-07291102p. Available from: National Technical Information Services, Springfield, VA 22161pp 13, 3261 . most sensitive to the effects of alcohol. ${ }^{\mathrm{B}}$ Choice reaction tests may also be more sensitive than pen and paper psychomotor tests of postanesthetic dysfunction.

This study has several limitations. Healthy volunteers differ from patients, who may experience perioperative anxiety, sleep deprivation, and postoperative pain and discomfort. Most patients receive postoperative opioids or antiemetics. These factors many delay the recovery of driving skills. Thus, the results were obtained without premedication and other adjuvants in the perianesthetic period. Further studies are warranted on ambulatory surgical patients.

Although the learning effect could improve driving performance on the driving simulator, two training sessions were conducted before the baseline session to minimize this effect. Although an interactive driving simulator was used, the visual scene and vehicle layout may have oversimplified driving conditions.

Light drinkers were excluded from the study because they seldom if ever consume alcohol to the $0.08 \%$ level. Earlier researchers have found that individuals in the light drinking category often had difficulty drinking the amount of alcohol required to reach this BAC. ${ }^{\mathrm{C}}$ Liver enzyme induction occurs in moderate to heavy drinkers and may lead to the rapid metabolism of anesthetic drugs. Thus, our results may not reflect the degree of drug-induced impairment among light drinkers. Although a balanced general anesthetic was administered, the fentanyl doses were low and no midazolam was given. A larger dose of fentanyl or the administration of midazolam could prolong the impairment of driving skill.

Since this is a pilot study, the sample size is small. Using the observed means and standard deviations in the data, we had approximately $80 \%$ power to detect a $10 \%$ increase in MRT, a $20 \%$ increase in lane deviation, and about a $100 \%$ increase in the number of collisions and in the number of times over speed limit. Some of the differences between the alcohol and other two groups were even smaller (approximately $5-7 \%, 10 \%$, $60 \%$ and $60 \%$, respectively). Therefore, most of these relatively large differences were not statistically significant. More patients need to be studied in the future.

In summary, there was no statistically significant difference with respect to the four driving performance variables between two, three, and four hours postanesthesia and the corresponding control sessions, respectively. When comparing the alcohol and control sessions, statistical significance was achieved in lane

C Burns M. Southern California Research Institute. Personal communication. 1999. 
deviation at $\mathrm{BAC} 0.079 \%(P=0.006)$. The GA and alcohol session were significantly different at two hours postanesthesia and a BAC $0.079 \%(P=0.042)$ in terms of the number of collisions, and at three hours postanesthesia and BAC $0.06 \%(P=0.019)$ in terms of the number of times over the speed limit.

This study suggests that some driving skills return within two hours after one half hour of GA of propofol, desflurane and fentanyl in young volunteers. Small changes in absolute values of performance during a 20 min period are associated with large changes in risk of an accident when millions of people drive for many hours in an impaired condition. Although driving performance has returned to baseline by $24 \mathrm{hr}$ postanesthesia, a larger prospective study of ambulatory surgical patients involving driving simulation or on-the-road studies would help to determine when patients can safely resume driving in the postanesthetic period.

\section{Acknowledgement}

We acknowledge Dr. Gabor Mezei for his assistance in statistical analysis.

\section{References}

1 Wetchler BV. Outpatient Anesthesia, 2nd Ed. Philadelphia: JB Lippincott Company; 1992: 1389.

2 Korttila K. Recovery from outpatient anaesthesia. Factors affecting outcome. Anaesthesia 1995; 50(Suppl): 22-8.

3 Korttila K. Recovery period and discharge. In: White PF. (Ed.). Outpatient Anesthesia. New York: Churchill Livingston Inc.; 1990: 369-1.

4 Korttila K, Tammisto T, Ertama P, Pfäffli P, Blomgren E, Häkkinen $S$. Recovery, psychomotor skills, and simulated driving after brief inhalational anesthesia with halothane or enflurane combined with nitrous oxide and oxygen. Anesthesiology 1977; 46: 20-7.

5 Linnoila $M$, Mattila MJ. Drug interaction on psychomotor skills related to driving: diazepam and alcohol. Eur J Clin Pharmacol 1973; 5: 186-94.

6 Korttila K. Psychomotor skills related to driving after intramuscular lidocaine. Acta Anaesthesiol Scand 1974; 18: 290-6.

7 Korttila K, Häkkinen S, Linnoila M. Side effects and skills related to driving after intramuscular administration of bupivacaine and etidocaine. Acta Anaesthesiol Scand 1975; 19: 384-91.

8 Korttila $K$, Linnoila $M$. Psychomotor skills related to driving after intramuscular administration of diazepam and meperidine. Anesthesiology 1975; 42: 685-91.

9 Korttila K, Linnoila $M$. Recovery and skills related to driving after intravenous sedation: dose-response relationship with diazepam. Br J Anaesth 1975; 47: 457-63.
10 Korttila K, Linnoila M. Amnestic action of and skills related to driving after intravenous flunitrazepam. Acta Anaesthesiol Scand 1976; 20: 160-8.

11 Seppala T, Korttila K, Häkkinen S, Linnoila $M$. Residual effects and skills related to driving after a single oral administration of diazepam, medazepam or lorazepam. Br J Clin Pharmacol 1976; 3: 831-41.

12 Korttila $K$. Lack of impairment in skills related to driving after intramuscular administration of prilocaine or mepivacaine. Acta Anaesthesiol Scand 1977; 21: 31-6.

13 Cahalan D, Cisin I, Crossley HM. American Drinking Practices. New Brunswick: Rutgers, 1969: 49.

14 Newman MG, Trieger N, Miller JC. Measuring recovery from anesthesia - a simple test. Anesth Analg 1969; 48: 136-40.

15 Lichtor JL. Recovery testing and evaluation. In: White PF (Ed.). Ambulatory Anesthesia and Surgery, 2nd ed. London: W. B. Saunders Company Ltd.; 1997: 469-70.

16 Thapar P, Zacny JP, Choi M, Apfelbaum JL. Objective and subjective impairment from often-used sedative/analgesic combinations in ambulatory surgery, using alcohol as a benchmark. Anesth Analg 1995; 80: 1092-8.

17 Chung F. Recovery pattern and home-readiness after ambulatory surgery. Anesth Analg 1995; 80: 896-902.

$18 \mathrm{Ogg} T W$. An assessment of postoperative outpatient cases. Br Med J 1972; 4: 573-6.

19 Korttila K, Linnoila M, Ertama P, Häkkinen S. Recovery and simulated driving after intravenous anesthesia with thiopental, methohexital, propanidid, or alphadione. Anesthesiology 1975; 43: 291-9. 